\title{
ECOSSISTEMAS INDUSTRIAIS COMO ECO-INOVAÇÃO COERENTE COM A CONSTRUÇÃO DE UMA ECONOMIA VERDE
}

\author{
Felipe Nogueira da Cruz ${ }^{1}$ \\ Debora Nayar Hoff ${ }^{2}$
}

\section{RESUMO}

Face às evidências da gestação de uma crise ambiental, diversos atores têm pontuado a importância das estruturas industriais para o estabelecimento de estratégias de desenvolvimento favoráveis à conservação da qualidade dos serviços ecossistêmicos. Nesse particular, a corrente conhecida como Ecologia Industrial advoga a reestruturação da indústria sob o formato de um sistema fechado, baseado em relações simbióticas e intrinsecamente ajustado às tolerâncias e características dos sistemas naturais: o Ecossistema Industrial. Este trabalho investigou como os Ecossistemas Industriais constituem um tipo de eco-inovação coerente com a construção de uma Economia Verde. Verificou-se que os Ecossistemas Industriais oferecem oportunidades de investimento e emprego em consonância com as necessidades de conservação do capital natural. Ademais, eles fornecem fortes evidências de que os esforços inovativos na direção de tecnologias ambientalmente seguras podem induzir ganhos econômicos e ambientais, constituindo uma estratégia viável no direcionamento de uma recuperação econômica verde.

Palavras-chave: Ecossistemas Industriais; Eco-inovação; Recuperação econômica verde.

\section{ABSTRACT \\ Given the evidence of the gestation of an environmental crisis, many players have punctuated the importance of industrial structures for establishing development strategies conducive to preserving the quality of ecosystem services. In this respect, the current known as Industrial Ecology advocates industry restructuring under the format of a closed system based on symbiotic and intrinsically adjusted to the tolerances and characteristics of natural systems: an Industrial Ecosystem. This article provides a literature review and analyzes how Industrial Ecosystems constitute a kind of eco-innovation consistent with the construction of a Green Economy. It was observed that the Industrial Ecosystems provide opportunities for investment and employment in line with the needs of conservation of natural capital. Industrial Ecosystems

\footnotetext{
${ }^{1}$ Professor Assistente do Instituto de Ciências Sociais Aplicadas da Universidade Federal de Juiz de Fora, Campus Governador Valadares. Doutorando em Ciência Econômica pela Universidade Estadual de Campinas

2 Professora pesquisadora do PPGA da Universidade Federal do Pampa, Campus Santana do Livramento. Doutora em Agronegócios - CEPAN - UFRGS.
} 
offer strong evidence that the innovative efforts towards environmentally friendly technologies can induce economic and environmental gains, and constitute a useful strategy in targeting a green economic recovery.

Keywords: Industrial Ecosystems; Eco-innovation; Green economic recovery.

\section{Classificação JEL: Q57 - Ecological Economics: Industrial Ecology 1. INTRODUÇÃO}

O aumento da eficiência na indústria seguiu uma trajetória tecnológica no sentido proposto por Nelson e Winter (1977) e Dosi (1982) -, na qual os avanços técnicos se deram com base na utilização ilimitada de recursos naturais de baixa entropia ${ }^{3}$ e na disposição irrestrita de resíduos no meio ambiente. Esse movimento estabeleceu um modelo industrial fundamentado na linearidade dos fluxos de matéria e energia. Nesse esquema, a energia e a matéria utilizadas no processo de transformação, tomadas como disponíveis de forma infinita, fluem da biosfera para a indústria. A indústria, por sua vez, emite rejeitos de maneira ilimitada, os quais retornam para a biosfera sob a forma de poluição do ar e da água ou de resíduos sólidos.

Esse modelo tradicional de indústria passou a ser concebido como a chave para o desenvolvimento das nações, principalmente a partir da sua difusão pelas economias avançadas durante todo o século $\mathrm{XX}$. Os anos "gloriosos" do pós-Segunda Guerra Mundial contribuíram para a propagação desse ideário. Nesse período, os países industrializados apresentaram altas taxas de crescimento com emprego elevado, consubstanciando o que ficou conhecido como Estado de Bem-Estar (Welfare State). No entanto, os custos ecológicos desses avanços foram bastante elevados, uma vez que as externalidades geradas pela atividade industrial colocaram em risco a integridade dos recursos materiais e energéticos e, por conseguinte, a própria existência econômica das sociedades (SACHS, 2000; PACHECO, 2013).

A expansão contínua da atividade industrial tem provocado efeitos sistêmicos que contribuem significativamente para a degradação do meio ambiente. Os exemplos mais destacados por ambientalistas são o aquecimento global e a depleção da camada de ozônio. Dada a escala de produção atual, as emissões não tóxicas, como o dióxido de carbono, tornaram-se uma séria ameaça ao ecossistema global. É com base nessa avaliação que diversos estudiosos têm diferenciado "crescimento econômico" de "desenvolvimento". Segundo Sachs (2000), desenvolvimento é um conceito pluridimensional que abarca três critérios essenciais: o social, o ecológico e o econômico. Seu objetivo pauta-se no bem-estar dos grupamentos humanos condicionado à dimensão ecológica. Essa condicionalidade baseia-se no postulado ético de

\footnotetext{
${ }^{3}$ A termodinâmica fundamenta-se na concepção de que a energia flui em uma só direção e tende a se dissipar em calor de baixa temperatura que não pode ser utilizado. Chama-se entropia essa soma de energia não aproveitável (CECHIN; VEIGA, 2010).
} 
solidariedade com as gerações futuras, isto é, de garantia das condições para que as gerações vindouras se desenvolvam satisfatoriamente.

A ideia de desenvolvimento ambientalmente sustentável popularizou-se em virtude dos diversos foros e conferências promovidos pela Organização das Nações Unidas (ONU), especialmente após a publicação do documento Our Common Future, em 1987. As discussões acerca da viabilidade dessa proposta centralizaram o debate no problema da relação entre o progresso material das organizações humanas e a conservação de recursos, reconhecendo a necessidade vital de novas estratégias de desenvolvimento. Mais recentemente, em resposta à crise econômica e financeira mundial de 2008, a ONU adotou a Economia Verde como uma das principais iniciativas para compatibilizar prosperidade socioeconômica e preservação do meio ambiente. Nessa perspectiva, as medidas governamentais atualmente direcionadas para superar os impactos da recente instabilidade do capitalismo mundial devem ser designadas sob o formato de uma recuperação econômica verde.

A Economia Verde compreende um modelo econômico com reduzida dependência em relação aos combustíveis fósseis (menos carbono intensivo), eficiente no uso dos recursos naturais e socialmente inclusivo. Tais características indicam que a busca pela sustentabilidade ambiental deve ser pautada pela máxima redução da intensidade material e energética dos processos produtivos, o que se encontra intimamente ligado às escolhas tecnológicas e aos arranjos institucionais de cada país. A mudança tecnológica na direção de tecnologias mais limpas e eficientes no uso dos serviços ecossistêmicos ocorre por meio das eco-inovações. Sendo assim, a utilização de tecnologias ambientalmente benignas constitui um dos principais pilares sobre os quais se sustenta a transição para uma Economia Verde. Na busca por um sistema econômico mais adequado à noção de limite de recursos, as inovações ambientais surgem como parte da solução do problema, induzindo mudanças no paradigma tecno-produtivo na direção de tecnologias que utilizem o capital natural de forma sustentável e que permitam a disposição adequada dos rejeitos industriais.

Em um artigo seminal publicado em 1989, Frosch e Gallopoulos utilizaram a metáfora dos ecossistemas naturais para analisar três setores específicos: plástico, ferro e platina. Esses autores chegaram à conclusão de que é possível perseguir um modelo mais integrado e limpo de produção industrial por meio de práticas como reciclagem, descarbonização, desmaterialização e troca de resíduos entre firmas. O Ecossistema Industrial, expressão cunhada pelos dois cientistas, corresponderia, portanto, a um sistema industrial mais fechado, com redução do uso de materiais virgens e recursos energéticos e mitigação dos problemas de desperdício e poluição (FROSCH; GALLOPOULOS, 1989).

Erkman (1997) reporta que uma série de projetos de Ecossistemas Industriais está em curso nos Estados Unidos, na Europa e na Ásia, em torno de atividades específicas, como usinas termelétricas, siderúrgicas, papel e celulose e cana-de-açúcar. Nesse contexto, o presente trabalho objetiva investigar como a estruturação de Ecossistemas Industriais constitui uma via possível para a eco-inovação coerente com a construção de uma Economia Verde. Entende-se que este é um esforço de pesquisa relevante, pois procura 
apreender a conformação de estratégias industriais aliadas à concepção de desenvolvimento sustentável.

Além desta introdução, o artigo está estruturado em mais quatro seções. A segunda seção discute os preceitos subjacentes ao estabelecimento de uma Economia Verde, bem como a importância da eco-inovação nesse processo. A terceira seção apresenta alguns conceitos e princípios da abordagem conhecida como Ecologia Industrial, dado que a temática Ecossistema Industrial surgiu a partir do desenvolvimento desse enfoque. Em seguida, a quarta seção trata especificamente dos Ecossistemas Industriais e seu papel na busca pela sustentabilidade ambiental. Por fim, a última seção apresenta as considerações finais.

\section{ECONOMIA VERDE E ECO-INOVAÇÕES}

Os acontecimentos ocorridos no início deste novo milênio consolidaram a visão de que a humanidade se depara com importantes desafios. Crises econômicas, sociais e ecológicas interdependentes exigem soluções inovadoras e mecanismos eficazes de intervenção que garantam a reprodução econômica das sociedades em um contexto de sérias limitações ecossistêmicas. Do ponto de vista ambiental, identificam-se crises relacionadas à perda de biodiversidade, mudanças climáticas, necessidade de uma revolução energética, escassez de água. As causas de todos esses problemas partem de um determinante comum: a depleção dos recursos naturais em virtude da expansão insustentável do sistema econômico (UNEP, 2011).

Diversos atores - cientistas, organismos multilaterais, organizações não governamentais, grupos de ambientalistas, entre outros - têm questionado a pertinência da reprodução de um modelo de crescimento insustentável como única alternativa disponível para as sociedades. Nesse contexto, um novo paradigma de organização das atividades econômicas vem sendo discutido: a Economia Verde ou Green Economy. A Green Economy Initiative é coordenada pelo United Nations Environment Programme (UNEP) e integra as nove iniciativas conjuntas adotadas pela ONU em resposta à crise econômica e financeira de 2008. A popularização do termo deu-se durante a Conferência das Nações Unidas sobre Desenvolvimento Sustentável, a Rio+20, realizada em 2012 no Brasil, embora sua origem possa ser traçada em discussões iniciadas há mais de duas décadas ${ }^{4}$.

UNEP (2010, p. 5) entende a Economia Verde como aquela "que resulta em melhorias no bem-estar e equidade social, reduzindo significativamente os riscos ambientais e a escassez ecológica". Trata-se de um modelo com

\footnotetext{
${ }^{4}$ Pearce et al. (1989) já haviam apontado que a engrenagem econômica provoca degradação ambiental, sendo essa tendência um sério obstáculo à obtenção do desenvolvimento sustentável. Segundo os autores, esse quadro implica na relevância de estratégias mais incisivas a fim de compatibilizar progresso socioeconômico e preservação do capital natural, indicando a necessidade de construção de uma Economia Verde.
} 
reduzida dependência em relação aos combustíveis fósseis e demais fontes energéticas não renováveis, eficiente no uso dos recursos naturais $e$ socialmente inclusivo. Nota-se, portanto, que a Economia Verde alia-se ao conceito de desenvolvimento sustentável, uma vez que abarca as três dimensões deste último: o social, o econômico e o ecológico. Nesse sentido, Almeida (2012) pondera que o conceito de Economia Verde não substitui o conceito de desenvolvimento sustentável. Na verdade, a Economia Verde pode ser vista como um conjunto de estratégias que possibilitam a obtenção de um desenvolvimento sustentável.

As discussões sobre Economia Verde incorporam a concepção de que sustentabilidade ambiental e avanço econômico não constituem objetivos antagônicos. Nessa perspectiva, muitos setores verdes - energia renovável e transporte sustentável, por exemplo - oferecem oportunidades de investimento e emprego com potencial para liderar a recuperação das nações afetadas pela recente instabilidade do capitalismo mundial. Segundo UNEP (2011), há um importante espaço para que acréscimos na renda e emprego se deem com base em investimentos que reduzam as emissões de dióxido de carbono e poluição em geral, melhorem a eficiência energética e material e previnam as perdas de biodiversidade e de serviços ecossistêmicos. Nessa mesma direção, a Organization for Economic Co-operation and Development (OECD) tem defendido que o atual período de recuperação econômica oferece uma atmosfera propícia para a implementação de reformas estruturais, abrindo oportunidades para ganhos tanto econômicos quanto ambientais (OECD, 2009a).

Os principais pilares sobre os quais se sustenta a transição para a Economia Verde são a realocação de investimentos e a crescente utilização de tecnologias ambientalmente seguras. A mudança tecnológica na direção de tecnologias mais limpas e eficientes no uso dos recursos naturais ocorre por meio das inovações. Ao inovar, a empresa está buscando solução para um determinado problema, que é resolvido dentro de um paradigma tecnológico, isto é, dentro de determinados padrões de soluções amplamente aceitos e baseados nos princípios das Ciências Naturais (DOSI, 1982). Entretanto, quando as dificuldades para achar soluções tornam-se crescentes, inclusive para as questões ambientais, há um forte incentivo para a mudança de paradigma tecnológico. Mas, essa não é uma condição suficiente, dado que o estabelecimento de um novo paradigma requer avanços no conhecimento básico, além de outros fatores institucionais e de mercado (LUSTOSA, 2011).

Freeman e Soete (2008) advertem que a grande dificuldade de uma agenda econômica verde reside na promoção de tecnologias sustentáveis dentro de uma economia de mercado que seleciona produtos e processos não com base em critérios ambientais, mas com base na lucratividade. Um meio para contornar essa dificuldade seria, conforme os autores, o desenvolvimento de políticas capazes de aproveitar as características cumulativas e autorreforçadoras das mudanças técnicas. Isso poderia ser obtido por meio de políticas que orientassem a produção para uma contínua busca de inovações e tecnologias em direções benéficas para o meio ambiente, induzindo à conformação de um novo paradigma tecnológico. 
De acordo com Bernauer et al. (2006), as inovações que promovem efeitos benéficos sobre o meio ambiente, independentemente destes resultados serem seu objetivo principal, são denominadas de eco-inovações ${ }^{5}$. Estas últimas incluem tanto inovações de produtos e processos quanto inovações organizacionais, sendo indispensáveis aprimoramentos, radicais ou não, nas práticas e desempenhos ambientais das corporações (OECD, 2009b). As eco-inovações, em última instância, possibilitam a obtenção e o aperfeiçoamento das chamadas Tecnologias Ambientalmente Saudáveis (TAS), definidas como "o conjunto de conhecimentos, técnicas, métodos, processos, experiências e equipamentos que utilizam os recursos naturais de forma sustentável e que permitem a disposição adequada dos rejeitos industriais, de forma a não degradar o meio ambiente" (LUSTOSA, 2011, p. 115-116).

Outro aspecto que diferencia a eco-inovação dos demais tipos de inovações refere-se ao problema da dupla externalidade. Além de produzir os efeitos spillovers típicos da maioria dos esforços de pesquisa e desenvolvimento, a eco-inovação também gera externalidades positivas em si mesma (RENNINGS, 1998). Beise e Rennings (2005) explicam que o problema da dupla externalidade ocorre porque é difícil para o inovador se apropriar dos lucros oriundos de uma inovação se o conhecimento correspondente é facilmente acessado pelos imitadores e se os benefícios ambientais gerados apresentam a característica de bem público. Esse problema reduz os incentivos que as firmas podem ter para investir em inovações ambientais. Disso apreende-se a necessidade de determinantes regulatórios e institucionais para impulsionar a mudança tecnológica na direção de tecnologias ambientalmente benignas.

Importante ressaltar que determinados tipos de regulação ambiental podem induzir as firmas a buscar e encontrar oportunidades de eco-inovação que, além de reduzir as externalidades adversas geradas por elas, resultam em ganhos de competitividade. Nessa direção, Porter e van der Linde (1995) argumentam que as regulações geram um conjunto de sinais para as firmas redirecionarem seus esforços inovativos para campos inexplorados. Destes esforços podem surgir innovation offsets ou compensações, o que significa que a redução das externalidades coincide com um aumento de produtividade dos recursos empregados na atividade de transformação. Os vínculos entre competitividade e meio ambiente, portanto, não constituem necessariamente trade-offs.

Andersen (2008) postula que uma teoria sobre eco-inovação deve enfatizar a dinâmica industrial, tomando como ponto de partida a empresa e a forma em que ela organiza a produção e o aprendizado em face de um mercado mundial em rápida transformação. A firma, no centro da análise, deve

\footnotetext{
${ }^{5} \mathrm{Na}$ literatura internacional, as atividades inovativas que buscam tecnologias mais limpas e eficientes no uso dos recursos naturais são identificadas pelos termos ecoinovação (eco-innovation), inovação verde (green innovation), inovação sustentável (sustainable innovation), inovação ambiental (environmental innovation) e cleaninnovation. Dentre estes, a eco-inovação e a inovação ambiental têm sido os mais usados (BERNAUER et al., 2006; DE MARCHI, 2012).
} 
ser vista como uma eco-inovadora potencial capaz de obter ganhos econômicos com a melhora de seu desempenho ambiental, e não como um agente poluidor. Essa perspectiva alinha-se àquela defendida pelos organismos multilaterais (UNEP, 2011; OECD, 2009a), priorizando as oportunidades que o "esverdeamento" do mercado oferece.

Dado que os fatores institucionais e culturais desempenham um papel importante na geração e comercialização de conhecimento, Lustosa (2011) afirma que a inovação ambiental não é resultado de uma decisão baseada em fatores internos à firma, mas de interações complexas entre ela e seus clientes e fornecedores, de um contexto mais amplo, que inclui o ambiente institucional, cultural e social, a infraestrutura científica e tecnológica, aspectos macroeconômicos, as medidas de caráter regulatório e o grau de competição do mercado. Considerando esta especificidade, Rennings (2000) identifica três conjuntos de determinantes da adoção de eco-inovações: o desenvolvimento tecnológico (technology push), os fatores oriundos da demanda (market pull) e um determinante derivado do ambiente regulatório (regulatory push/pull-effect), aspecto este que se diferencia das inovações em sentido mais amplo.

Andersen (2008) destaca que as eco-inovações devem ser examinadas sob um enfoque sistêmico. Para tanto, esse autor estabelece uma taxonomia que identifica tipos-chave de inovação ambiental, refletindo suas diferentes funções. São sugeridas, assim, cinco categorias:

1. Eco-inovações aditivas (add-on): (tecnologias e serviços de manuseio de poluição e de recursos). São produtos (bens e serviços) que melhoram o desempenho ambiental do consumidor. O produto em si não precisa necessariamente ser ambientalmente amigável, o foco é no processo. Lidam com soluções ambientais nas saídas do processo (limpeza, diluição, reciclagem, medição, controle e transporte de emissões) e no lado da entrada de recursos (extração e suprimento de recursos naturais e energia). A conservação da natureza, seja pelos inputs ou outputs, pode ser inclusa (ANDERSEN, 2008);

2. Eco-inovações integradas: (processos e produtos de tecnologia mais limpa). São as inovações integradas que tornam tanto o processo de produção quanto os produtos mais eco-eficientes do que os processos ou produtos similares. O investimento neste tipo de inovação pode tanto ser feito para tornar a empresa mais eco-eficiente do que os concorrentes, como apenas para melhorar a produtividade da firma. Estas inovações, técnicas ou organizacionais, permitem alcançar eficiência em energia e recursos, aumentar reciclagem ou viabilizar a substituição de material tóxico, mudança nas práticas de produção e consumo. O "esverdeamento" dos produtos é observado na sua relação com similares, podendo mudar ao longo do tempo, exigindo continuidade em relação a um objetivo móvel (ANDERSEN, 2008);

3. Produtos alternativos eco-inovados: (novos caminhos tecnológicos). São inovações que representam uma mudança tecnológica radical. A questão não é ter um produto ou processo mais limpo que os demais. Ao invés disso, oferecer uma solução ou alternativa muito diferente e ambientalmente mais benigna. Geralmente têm um amplo efeito sistêmico, sendo constituídos sobre novas teorias, capacitações e práticas, exigindo mudanças nos padrões de produção e consumo. A dimensão ambiental reside 
somente no design da produção/produto, que deve ser mais verde que a alternativa (não similar). O método de produção em si não precisa ser limpo e, em alguns casos, atrai pouca atenção. São exemplos as tecnologias de energia renovável e a produção agrícola orgânica (ANDERSEN, 2008);

4. Eco-inovações macro-organizacionais: (novas estruturas organizacionais). Estas inovações propõem novas soluções para um caminho eco-eficiente de organização da sociedade. Isto significa novos caminhos de organização da produção e do consumo em um nível mais sistêmico, implicando em novas interações funcionais entre as organizações (simbiose industrial, Ecossistemas Industriais), entre famílias e ambiente de trabalho e novas formas de organizar cidades e sua infraestrutura técnica (ecologia urbana). Mudam o planejamento regional e físico e a infraestrutura técnica de várias formas, sendo consideradas inovações tanto organizacionais quanto técnicas. Exigem cooperação da esfera pública (por ocorrerem em grande escala neste domínio) com as empresas, visando desenvolver novas soluções (ANDERSEN, 2008);

5. Eco-inovações de propósito geral: (mudanças de paradigma tecnológico). Certas tecnologias de uso geral afetam profundamente a economia e o processo inovativo, em função das relações que possuem com uma série de outras inovações tecnológicas. Estas tecnologias são usadas como referência para definir o paradigma tecno-dominante em determinados momentos do tempo. Mudanças nas tecnologias de propósito geral são tão fundamentais que terão sempre efeito importante sobre as eco-inovações, merecendo então uma atenção especial. Por poderem gerar efeitos tanto negativos como positivos, tecnologias como as de informação e comunicação (TIC), biotecnologia, e, recentemente, a nanotecnologia, merecem uma atenção especial no que diz respeito também à eco-inovação (ANDERSEN, 2008).

Em seu esforço de desenvolver uma classificação abrangente, Andersen (2008) descreve uma trajetória de progresso técnico, desde a adoção de serviços de controle da poluição e do uso de recursos até a mudança do paradigma tecnológico, momento em que a Economia Verde é alcançada. Esse processo envolve a implantação de eco-inovações macro-organizacionais, isto é, novas estruturas de organização da produção e do consumo em um nível sistêmico. Especificamente no âmbito industrial, isso significa a conformação de estruturas produtivas conhecidas como Ecossistemas Industriais, baseadas no fechamento do ciclo matéria-energia e na simbiose industrial. Considerando que a temática Ecossistema Industrial surgiu a partir do desenvolvimento do campo de estudos multidisciplinar conhecido como Ecologia Industrial, a próxima seção apresenta os principais conceitos desse último enfoque. Posteriormente, na quarta seção, discutir-se-á os Ecossistemas Industriais e seu papel na busca pela sustentabilidade ambiental.

\section{ECOLOGIA INDUSTRIAL: O FECHAMENTO DO CICLO MATÉRIA- ENERGIA E A SIMBIOSE INDUSTRIAL}


$\mathrm{Na}$ Ciência Econômica, o estudo sobre as relações entre sistema econômico e o sistema natural tem sido dominado pela abordagem neoclássica. Esse enfoque, conhecido como Economia Ambiental, examina os vínculos entre meio ambiente e competitividade a partir do marco teórico da economia do bem-estar, comparando os custos e os benefícios sociais da adoção de medidas de segurança ambiental. Entende-se que os custos constituem um resultado espontâneo do esforço empreendido pelas firmas para melhorar seu desempenho ambiental ${ }^{6}$, assim como dos recursos necessários ao monitoramento e cumprimento das regulações estabelecidas pelo Estado. Os benefícios, por sua vez, são situados exclusivamente na esfera social, o que implica negligenciar possíveis vantagens competitivas que as firmas podem obter em termos de redução de custos de produção, melhorias na qualidade de produtos e aumento na participação de mercado (LÓPEZ, 1996; ANDERSEN, 2008).

Amparando-se na aplicação de leis econômicas fundamentais em um contexto estático, a Economia Ambiental propõe a "internalização das externalidades", isto é, o estabelecimento de compensações monetárias para reparar os prejuízos causados contra o meio ambiente. Predomina a noção de que os danos provocados pela atividade econômica, tais como contaminação e poluição em suas diversas formas, constituem falhas que devem ser precificadas e, portanto, reduzidas à lógica de mercado. Além disso, não há uma análise do modelo de indústria historicamente construído, muito menos do padrão tecnológico vigente como fatores que agravam os problemas ambientais (ANDERSEN, 2008).

Insatisfeitos com o ideário proposto pelo arcabouço neoclássico, alguns estudiosos iniciaram uma reflexão crítica tomando como referência as análises do economista romeno Georgescu-Roegen ${ }^{7}$. O resultado foi o desenvolvimento de uma visão sistêmica e integrada de todos os componentes do sistema econômico e suas relações com a biosfera, consubstanciando a corrente conhecida como Economia Ecológica. Essa perspectiva enfatiza o substrato biofísico das atividades humanas, isto é, os padrões complexos dos fluxos de matéria e energia dentro e fora do processo de transformação, em contraste com as teorias correntes que consideram a economia em termos de unidades monetárias abstratas. Ademais, advoga que a qualidade dos serviços providos pelos ecossistemas dependerá da extensão na qual a produção agrícola e industrial e os processos urbanos forem reestruturados para operar em harmonia com os componentes do meio ambiente.

\footnotetext{
${ }^{6}$ A análise econômica tradicional parte da concepção de que, confrontada com um conjunto de combinações insumo-produto, a firma atua racionalmente escolhendo a combinação técnica que garanta lucro máximo. Nesse sentido, qualquer fator que obstaculize a livre atuação da empresa - uma regulação ambiental, por exemplo - fará com que esse agente incorra em ineficiências, elevando seus custos de operação.

7 Nicholas Georgescu-Roegen foi quem primeiro utilizou os princípios da termodinâmica para explicar as barreiras impostas pela natureza à expansão econômica. Para Georgescu, a economia é um sistema dissipativo sustentado por um fluxo metabólico. Sua expansão dentro de um sistema finito e materialmente fechado (a biosfera) exige um custo. Se esse custo for maior que o benefício gerado pelo crescimento, este estará sendo antieconômico (CECHIN; VEIGA, 2010).
} 
Considerando estes aspectos, mas debruçando-se sobre o processo produtivo e as possibilidades de ajuste que este pode ou tem que sofrer para adaptar-se às noções de limites ecossistêmicos que a Economia Ecológica coloca em pauta, alguns estudiosos, em grande parte ligados às discussões das Engenharias de Produção, Química e Ambiental, desenvolveram um enfoque conhecido como Ecologia Industrial ${ }^{8}$. Desrochers (2002) identifica esse enfoque como uma das perspectivas mais influentes que emergiram nos anos recentes no debate sobre a interlocução entre a indústria e o meio ambiente.

A Ecologia Industrial entende o desenvolvimento tecnológico no contexto dos ecossistemas maiores que o suportam, examinando as fontes de recursos utilizados na esfera da produção e a capacidade de o meio ambiente absorver os rejeitos industriais. O sistema econômico é apreendido como um subsistema de um universo maior e mais complexo, uma vez que a indústria depende dos serviços e recursos providos pela biosfera, da qual não pode ser dissociada (LIFSET; GRAEDEL, 2002; PACHECO, 2013).

Assim como os ecossistemas naturais, o sistema industrial é descrito como uma distribuição de fluxos de matéria e energia. Essa analogia com a Biologia é aplicada essencialmente ao nível dos distritos e regiões industriais, importando noções da Ecologia para a construção de um modelo de análise dos relacionamentos interfirma e de sua interface com o meio ambiente. É nesse sentido que se procura entender o metabolismo industrial, isto é, o conjunto de entradas e saídas de matéria e energia presentes na indústria, desde a extração desses recursos da natureza até sua reintegração ao ambiente abiótico (LIFSET; GRAEDEL, 2002; ERKMAN, 1997).

O'Rourke et al. (1996) destacam que a Ecologia Industrial abriga um grupo heterogêneo de pesquisadores, gestores, engenheiros, consultores e analistas políticos. Segundo esses autores, o enfoque abrange tanto aqueles que apostam em mudanças incrementais da estrutura industrial quanto os defensores de uma transformação radical da indústria. Desse modo, a Ecologia Industrial pode ser entendida mais como um amplo espectro de conceitos do que um marco teórico unificado, o que explica as diferentes formas em que ela é elucidada pelos estudiosos.

Frosch e Uenohara (1994), por exemplo, apontam que a Ecologia Industrial fornece um enfoque sistêmico e integrado que auxilia o manejo dos impactos ambientais provocados pelos processos industriais. Tal abordagem postula a necessidade de um entendimento apropriado do metabolismo industrial e de conhecimentos específicos sobre usos alternativos para os resíduos, além de mecanismos que estimulem a otimização do uso de materiais e energia, a exemplo do mercado, incentivos e estruturas

8 As discussões propostas pela Ecologia Industrial aproximam-se daquelas da Economia Ecológica. Neste artigo, destaca-se a vinculação via tecnologia. Por um lado, na busca por um sistema econômico mais adequado à noção de limites ecossistêmicos, as inovações surgem como parte da solução do problema, particularmente aquelas que permitem reduzir as pressões sobre o ambiente natural, isto é, as eco-inovações. Por outro lado, a tecnologia constitui uma variável fundamental no esquema teórico proposto pela Ecologia Industrial, conforme será esclarecido ao longo desta seção. 
regulatórias. Allenby (1992), por sua vez, percebe a Ecologia Industrial como o instrumento por meio do qual um estado de desenvolvimento sustentável é garantido. Ela consiste, segundo esse autor, em uma visão sistêmica da atividade industrial e sua inter-relação com os sistemas biológicos, físicos e químicos, com o intuito de sustentar a qualidade de vida indefinidamente, dada a contínua evolução econômica, cultural e tecnológica.

O que se pretende enfatizar com as duas definições apresentadas é que, baseada nas perspectivas dos autores acerca do estado atual da indústria e do meio ambiente, a Ecologia Industrial pode assumir traços ideológicos distintos. Se, por um lado, ela constitui uma arena de defesa das melhorias de eficiência incrementais em curso na indústria, por outro, ela compreende um paradigma revolucionário que deve ser assimilado pela humanidade de forma a garantir a própria existência econômica das sociedades. Importante ressaltar que, independentemente de tais divergências, o amplo espectro da Ecologia Industrial desemboca em diretrizes gerais que norteiam seu desenvolvimento. Nesse particular, Tibbs (1993) enumera seis conceitos que exprimem tais diretrizes: i) metabolismo industrial; ii) sistemas energéticos; iii) interfaces com a biosfera; iv) desmaterialização/descarbonização; v) Ecossistemas Industriais; e vi) política de inovação.

A Ecologia Industrial constitui uma visão sistêmica e integrada de todos os componentes da Economia Industrial e suas relações com a biosfera, enfatizando o substrato biofísico das atividades produtivas. Disso apreende-se a relevância de conceitos como metabolismo industrial, sistemas energéticos e interfaces com a biosfera. A Ecologia Industrial também entende as trajetórias tecnológicas como um elemento crucial, mas não exclusivo, para a reestruturação do sistema industrial em níveis ambientalmente sustentáveis. Apreende-se agora a importância de conceitos como desmaterialização/descarbonização, Ecossistemas Industriais e política de inovação, uma vez que todos eles perpassam a esfera do desenvolvimento tecnológico (TIBBS, 1993).

Para que a Ecologia Industrial alcance seus objetivos básicos é necessário que ocorra o que se entende por fechamento do ciclo ou do sistema, isto é, a transformação dos sistemas industriais lineares em sistemas mais fechados, onde a utilização de materiais e energia é otimizada e há menos dependência de recursos naturais não renováveis. Além do fechamento do ciclo matéria-energia, a análise das interrelações entre os diversos agentes que compõem o sistema industrial constitui outro aspecto crucial da Ecologia Industrial. Aqui, mais uma vez, os estudiosos utilizam a analogia com a Biologia para elucidar a simbiose industrial como fator determinante para a reestruturação da indústria em níveis ambientalmente seguros. Na verdade, como destaca Pacheco (2013), a centralidade da simbiose industrial advém da operacionalidade do fechamento do ciclo, já que é por meio dela que se torna possível reaproveitar os fluxos do metabolismo industrial através de uma relação de mutualismo.

A simbiose descreve a relação biológica na qual pelo menos dois organismos diferentes realizam trocas que são mutuamente benéficas. Aplicado à Ecologia Industrial, esse conceito refere-se à cooperação entre atores geograficamente próximos, trocando ou compartilhando matéria, 
energia, informação ou subprodutos. Nesse processo, o benefício coletivo é maior do que a soma dos benefícios individuais quando cada agente age isoladamente. O benefício compartilhado é resultado de ganhos sinérgicos obtidos com os usos alternativos para os subprodutos, com o compartilhamento de estruturas físicas e com a prestação conjunta de serviços (CHERTOW, 2004; PACHECO, 2013).

Em geral, a simbiose industrial ocorre em espaços locais ou regionais. $O$ aumento da distância entre as firmas reduz as oportunidades de troca porque não é eficiente transportar materiais específicos para além das fronteiras regionais. O calor e o vapor, por exemplo, se dissipam rapidamente, enquanto que a água necessita de tubulações especiais, envolvendo custos adicionais. Ademais, é importante considerar a degradação energética que envolve o transporte dos subprodutos (CHERTOW, 2004; PACHECO, 2013).

A simbiose industrial engaja as empresas e indústrias, tradicionalmente separadas, em um modelo coletivo, cuja troca física de matéria, energia e informação promove vantagens competitivas. As estratégias de colaboração e as possibilidades sinérgicas oferecidas pela proximidade geográfica induzem novas formas de comportamento interfirma baseadas na cooperação. Conforme descreve Ayres (2002), os benefícios resultantes da simbiose industrial podem ser entendidos como economias de integração não negligenciáveis, com impactos positivos na elevação da eco-eficiência das operações industriais.

Com base no critério de fechamento do ciclo matéria-energia e na simbiose industrial, diversos autores, entre eles Allenby (1992), descrevem uma economia composta por sistemas mais eficientes que estimulam o fluxo cíclico dos recursos, provocando, assim, menos impactos sobre o meio ambiente. Tais sistemas são chamados de Ecossistemas Industriais, tema discutido na próxima seção.

\section{ECOSSISTEMAS INDUSTRIAIS COMO FONTE DE GANHOS ECONÔMICOS E AMBIENTAIS}

Frosch e Gallopoulos (1989) pioneiramente utilizaram a expressão Ecossistema Industrial para descrever determinado tipo de arranjo produtivo no qual os efluentes de um processo servem de insumos para outro. A preocupação fundamental não recai sobre a quantidade absoluta de rejeitos que são gerados na atividade industrial, mas sim nas potencialidades de conversão dos mesmos em insumos úteis. Por isso, Tibbs (1993) sugere uma ampla reconceituação dos resíduos como a chave para a criação de Ecossistemas Industriais.

Para Gertler (1995), o Ecossistema Industrial consiste de uma comunidade de empresas localizadas em uma determinada região que interagem trocando e utilizando resíduos materiais e energéticos. Esse modelo de cooperação minimiza a degradação ambiental. Nesse sentido, é lícito considerar os Ecossistemas Industriais como a manifestação da aplicação dos princípios da Ecologia Industrial no nível interfirma. 
No que tange ao fluxo de matéria, a perspectiva dos Ecossistemas Industriais advoga a manutenção da capacidade sistêmica de reprodução dos recursos naturais e de assimilação de resíduos, o que poderia ser alcançado por meio da reciclagem. Em relação à produção e ao consumo de energia, essa corrente adverte a necessidade de se reduzir o uso de combustíveis fósseis e de outras energias não renováveis. Esse objetivo poderia ser alcançado por meio da utilização eficiente de energias renováveis em diferentes níveis de qualidade (energia em cascata).

Tanto a reciclagem da matéria quanto a ideia de energia em cascata fornecem a base para se pensar as formas de conectar diferentes processos geradores de resíduos, plantas e indústrias em uma rede operacional que minimiza a quantidade total de matéria e energia que é eliminada em vazadouros ou que é perdida em processos intermediários. O conceito chave da abordagem dos Ecossistemas Industriais é a visão dos processos industriais como sistemas interativos ao invés de componentes isolados. Ao fomentar a cooperação entre as firmas, tal enfoque diferencia-se de outras iniciativas que incidem sobre a unidade produtiva individual. Cooperando umas com as outras, as empresas poderiam melhorar seu desempenho econômico e ambiental.

Korhonen (2001) afirma que o conceito de Ecossistema Industrial busca captar a emergência de um sistema industrial fundamentado na cooperação entre unidades produtivas individuais, de forma que estas utilizem seus subprodutos como insumos úteis, reduzindo o uso de materiais virgens, bem como a emissão de rejeitos. Para esse autor, o termo faz analogia a alguns princípios dos ecossistemas naturais: i) roundput; ii) diversidade; iii) localidade; e iv) gradualismo.

Os ecossistemas naturais são adaptados às condições ambientais locais, respeitando seus limites. Os sistemas industriais tradicionais superam tais limites por meio da importação de recursos. Ademais, guiam-se pela crença, teoricamente estabelecida, de que o capital natural pode ser substituído indefinidamente por inovação tecnológica ou capital construído. No entanto, para alcançar a metáfora de um ecossistema, a indústria deverá substituir recursos importados por recursos renováveis locais, além de reciclálos por meio do uso de subprodutos e do fluxo energético em cascata (roundput). Para tanto, deverá acompanhar o tempo cíclico dos recursos locais ao invés de exceder sua taxa de renovação (gradualismo), adaptando-se aos limites naturais da localidade. Dada a diversidade em atores, insumos, produtos, informação e em interdependência, deverá também promover relações simbióticas entre agentes e ecossistemas (KORHONEN, 2001).

Ainda conforme Korhonen (2001), a conformação de um Ecossistema Industrial envolve a transição de um fluxo linear de matéria-energia para um fluxo quasi-cíclico, onde os recursos e resíduos são limitados e o sistema opera por meio de uma reciclagem quase completa dos fluxos materiais. Em um Ecossistema Industrial ideal, ambos os sistemas (o subsistema industrial e a biosfera) operam de acordo com os quatro princípios descritos. Importante destacar que tais princípios descrevem um tipo ideal e, portanto, constituem diretrizes e direções iniciais para o desenvolvimento dos Ecossistemas Industriais. 
Com base no modelo cíclico do fluxo matéria-energia e nos quatro princípios citados por Korhonen (2001), a Figura 1 representa um Ecossistema Industrial ideal.

Figura 1

Ecossistema Industrial ideal

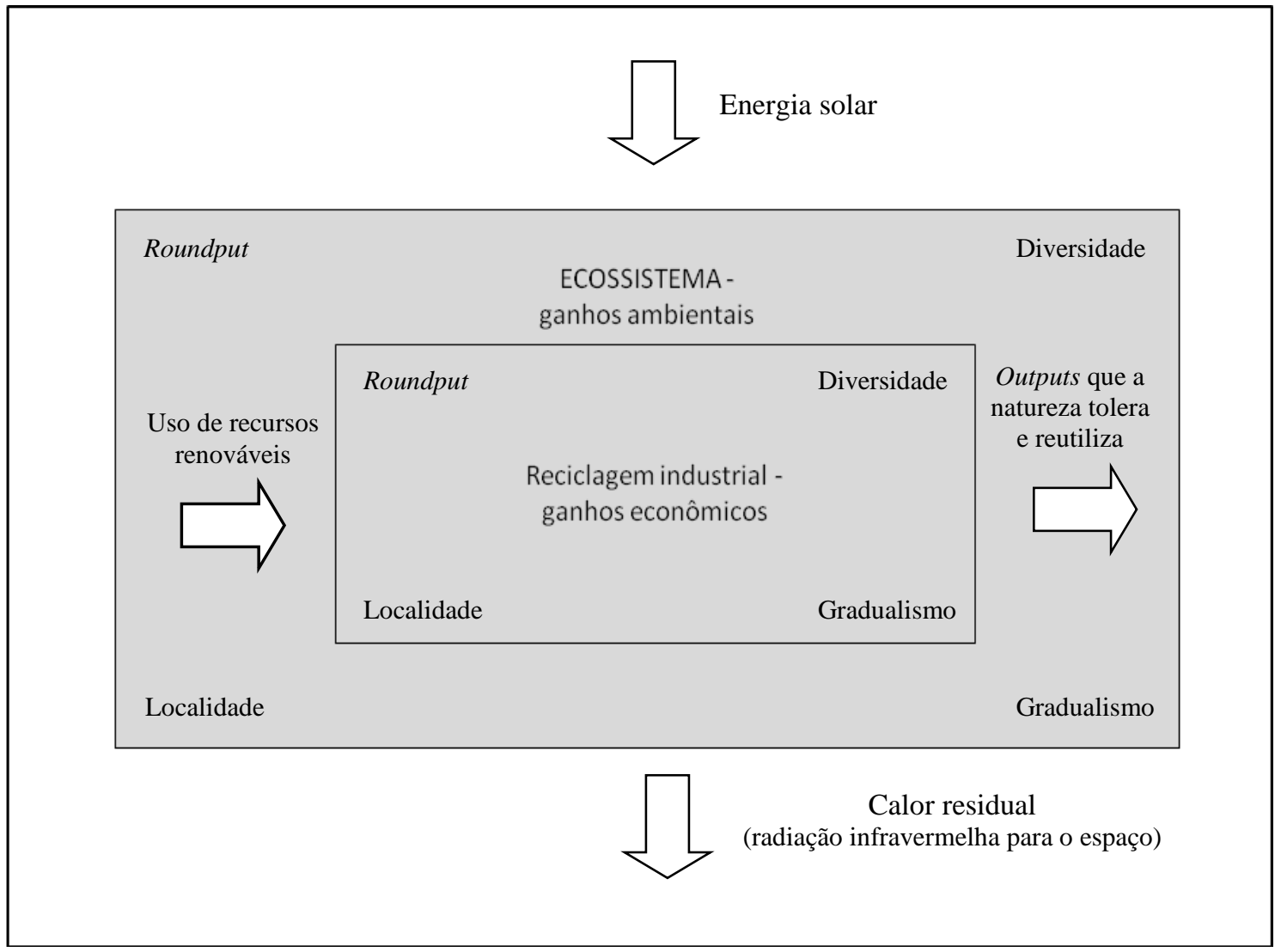

Fonte: Elaboração própria a partir de Korhonen (2001).

O modelo esquematizado parte da coexistência de dois sistemas: o subsistema industrial e o ecossistema natural, sendo que este último contém o primeiro. O único insumo do conjunto do sistema é a energia solar e o único subproduto é o calor residual. Os insumos do subsistema industrial incluem somente recursos renováveis, os quais são reciclados. A energia flui em cascata entre os diversos atores da indústria. Os produtos lançados no ecossistema natural incluem apenas materiais que o meio ambiente é capaz de absorver e reutilizar. Ademais, os dois sistemas operam de acordo com os mesmos princípios: roundput, diversidade, localidade e gradualismo. Tal modelo acarreta ganhos ambientais, uma vez que o uso de recursos virgens e a emissão de rejeitos são reduzidos. Ganhos econômicos também são possíveis por meio da redução dos custos associados à aquisição de matéria bruta e energia, bem como dos custos referentes à gestão dos resíduos.

Há o consenso de que a criação de um Ecossistema Industrial é altamente desejável do ponto de vista ambiental. No entanto, uma série de obstáculos impedem sua implementação. Em primeiro lugar, tem-se a ideologia econômica prevalecente. A teoria convencional afirma que os processos 
industriais são projetados para maximizar os benefícios imediatos do fabricante e a utilidade do consumidor, em vez de buscar o benefício do conjunto da economia. Erkman (1997) explica que as idéias econômicas tendem para a direção oposta daquilo que propõe a Ecologia Industrial, favorecendo a abertura dos ciclos de matéria e a obsolescência dos produtos.

Como escreve Sachs (2000), a eficiência econômica não pode ser mais avaliada unicamente por meio da rentabilidade da empresa, mas sim com base nas externalidades sociais e ecológicas. É necessário um tratamento holístico para que haja o equilíbrio entre os benefícios econômicos e as necessidades ambientais. Para tanto, como observam Frosch e Gallopoulos (1989), o conceito de Ecologia Industrial deve ser reconhecido e valorizado pelo Estado, por líderes da indústria e da mídia e pelo sistema educacional, de modo a favorecer a abordagem dos Ecossistemas Industriais.

Os rejeitos e efluentes oriundos da atividade produtiva representam apenas o lado da oferta do Ecossistema Industrial. Assim, uma segunda questão nos remete ao lado da demanda, isto é, ao papel do consumidor. Os resíduos gerados pelo consumo das famílias também devem ser usados como insumos úteis nos próximos ciclos de produção. Mudanças na produção, portanto, devem ser acompanhadas por alterações nos padrões de demanda dos consumidores e no tratamento dos materiais, uma vez comprados e utilizados (FROSCH; GALLOPOULOS, 1989).

Uma terceira barreira para a implementação de Ecossistemas Industriais refere-se ao padrão tecnológico vigente. Conforme pondera Sachs (2000), a tecnologia é uma variável fundamental, pois corresponde à maneira de relacionar o meio ambiente com os objetivos de progresso material da sociedade. Desse modo, grande esforço deve ser empreendido em direção a tecnologias que permitam aproveitar melhor a oferta potencial de recursos em bases sustentáveis.

Muitos autores visualizam a inovação tecnológica como o instrumento central para a solução dos problemas ambientais. Nesse particular, Lifset e Graedel (2002) destacam o papel das empresas: como lócus de expertise tecnológica, elas são agentes fundamentais para a reestruturação da indústria em um modelo ambientalmente seguro. Assim, por um lado, o papel das firmas é um tópico crucial a ser investigado pela Ecologia Industrial, bem como um componente fundamental para a adoção de uma política ambiental satisfatória. Por outro lado, o Ecossistema Industrial é uma eco-inovação, no sentido do arranjo produtivo que busca minimizar os impactos ambientais negativos, ao mesmo tempo que requer inovações que permitam o aumento de eficiência e novas possibilidades de aproveitamento de resíduos e subprodutos.

Como enfatizam Frosch e Gallopoulos (1989), harmonizar os desejos do desenvolvimento industrial global com as necessidades de segurança ambiental é um grande desafio. No entanto, os incentivos são óbvios: as empresas minimizarão seus custos e aumentarão sua competitividade ao aderirem a uma abordagem mais racional. Para além da retórica do desenvolvimento sustentável, uma motivação para a estruturação dos Ecossistemas Industriais é o incremento da competitividade: esse modelo é uma forma das empresas explorarem seus produtos e recursos, incluindo os resíduos, com maior eficiência. A criação de um Ecossistema Industrial, além 
de altamente vantajosa do ponto de vista ambiental, é também altamente lucrativa.

\section{CONSIDERAÇÕES FINAIS}

O modelo de indústria historicamente construído toma o meio ambiente como um recurso infinito, apoiando-se na concepção errônea de que os serviços "gratuitamente" ofertados pelos ecossistemas são ilimitados. Ao promover a utilização intensiva de insumos brutos, extraídos diretamente da natureza, e seu posterior descarte, ele não incentiva o reaproveitamento desses materiais nos ciclos produtivos subsequentes. Ademais, a utilização dos combustíveis fósseis instituiu um sistema industrial baseado em fontes de energia não renováveis, cujos impactos adversos se fazem sentir por meio da emissão de gases oriundos do processo de combustão.

Face às evidências da gestação de uma crise ambiental, diversos atores têm pontuado a importância das estruturas industriais para o estabelecimento de estratégias de desenvolvimento favoráveis à conservação da qualidade dos serviços ecossistêmicos. Nesse particular, a corrente conhecida como Ecologia Industrial advoga a reestruturação da indústria sob o formato de um sistema fechado e estável baseado em relações simbióticas, isto é, sob a perspectiva de um Ecossistema Industrial.

Os Ecossistemas Industriais buscam a conformação de estruturas produtivas intrinsecamente ajustadas às tolerâncias e características dos sistemas naturais. Além disso, eles promovem ganhos substanciais em produtividade. Em primeiro lugar, a necessidade de se alterar o design e o ciclo de vida dos produtos traduz-se no surgimento de bens com melhor desempenho ou qualidade superior. Para a firma, isso pode implicar diferenciação de produto e aumento da participação no mercado. Em segundo lugar, mudanças nos processos de produção induzem uma maior eficiência dos recursos empregados. Esse ganho de eficiência pode ser resultado de menores gastos com monitoramento e manutenção, economia de matériasprimas por meio do reuso ou reciclagem, utilização de subprodutos, menor consumo de energia e disposição mais segura de resíduos.

Dadas as vantagens ambientais e econômicas obtidas através da conformação dos Ecossistemas Industriais, entende-se que estes últimos são estratégias eco-inovativas viáveis para a construção de uma Economia Verde. Considerando o cenário favorável para a alocação das inversões em setores verdes - conforme sugerido por diversos órgãos multilaterais (OECD, 2009a; UNEP, 2011) -, os Ecossistemas Industriais oferecem oportunidades de investimento e emprego em consonância com as necessidades de conservação do capital natural. Isso revela que sustentabilidade ambiental e progresso socioeconômico não constituem objetivos antagônicos.

Percebe-se que, longe de uma oposição axiomática entre meio ambiente e competitividade, os Ecossistemas Industriais fornecem fortes evidências de que os esforços inovativos na direção de tecnologias ambientalmente seguras podem induzir ganhos de competitividade não negligenciáveis. Nesse sentido, as proposições da Ecologia Industrial constituem um instrumental relevante 
para o direcionamento das atividades de pesquisa e desenvolvimento, bem como das políticas em matéria ambiental no contexto de uma recuperação econômica verde.

\section{REFERÊNCIAS}

ALLENBY, B. R. Achieving Sustainable Development through Industrial Ecology. International Environmental Affairs, v. 4, n. 1, p. 56-68, 1992.

ALMEIDA, L. T. Economia verde: a reiteração de ideias à espera de ações. Estudos Avançados, v. 26, n. 74, p. 93-103, 2012.

ANDERSEN, M. M. Eco-innovation - towards a taxonomy and a theory. In: $25^{\text {th }}$ Celebration Conference 2008: Entrepreneurship and Innovation Organizations, Institutions, Systems and Regions. Copenhagen, 2008. Anais...

AYRES, R. U. On industrial ecosystems. In: AYRES, R. U.; AYRES, L. W. A handbook of Industrial Ecology. UK: Edward Elgar Publishing, 2002, p. 4459.

BEISE, M.; RENNINGS, K. Lead markets and regulation: a framework for analyzing the international diffusion of environmental innovations. Ecological Economics, v. 52, n. 1, p. 5-17, 2005.

BERNAUER, T.; ENGEL, S.; KAMMERER, D.; SEIJAS, J. Explaining Green Innovation: ten years after Porter's win-win proposition: how to study the effects of regulation on corporate environmental innovation? Politische Vierteljahresschrift, v. 39, p. 323-341, jun. 2006.

DE MARCHI, V. Environmental innovation and R\&D cooperation: empirical evidence from Spanish manufacturing firms. Research Policy, v. 41, n. 13, p. 614-623, 2012.

CECHIN, A.; VEIGA, J. E. O fundamento da Economia Ecológica. In: MAY, P. (Org.). Economia do Meio Ambiente: teoria e prática. $2^{-a}$ ed. Rio de Janeiro: Elsevier, 2010, p. 33-48.

CHERTOW, M. R. Industrial symbiosis. Encyclopedia of Energy, v. 3, p. 407415, 2004.

DESROCHERS, P. Industrial ecology and the rediscovery of inter-firm recycling linkages: historical evidence and policy implications. Industrial and Corporate Change, v. 11, n. 5, p. 1031-1057, 2002.

DOSI, G. Technological paradigms and technological trajectories. Research Policy, v. 11, n. 3, p. 147-162, 1982. 
EHRENFELD, J.; GERTLER, N. Industrial Ecology in practice: the evolution of interdependence at Kalundborg. Journal of Industrial Ecology, v. 1, n. 1, p. 67-79, 1997.

ERKMAN, S. Industrial Ecology: an historical view. Journal of Cleaner Production, v. 5, n. 1-2, p. 1-10, 1997.

FREEMAN, C.; SOETE, L. A economia da inovação industrial. Campinas: Editora da Unicamp, 2008.

FROSCH, R. A.; GALLOPOULOS, N. E. Strategies for Manufacturing. Scientific American, v. 261, n. 3, p. 144-152, 1989.

FROSCH, R. S.; UENOHARA, M. Chairmen's Overview. In: RICHARDS, D. J.; FULLERTON, A. B. Industrial Ecology U.S. Japan Perspectives. National Academy of Engineering, 1994.

Gertler, N. Industrial ecosystems: developing sustainable industrial structures. 1995. Tese (Master of Science in Technology and Policy and Master of Science in Civil and Environmental Engineering) - Technology and Policy Program and the Department of Civil and Environmental Engineering, Massachusetts Institute of Technology, Cambridge, 1995.

KORHONEN, J. Four ecosystem principles for an industrial ecosystem. Journal of Cleaner Production, v. 9, n. 3, p. 253-259, 2001.

LIFSET, R.; GRAEDEL, T. E. Industrial Ecology: goals and definitions. In: AYRES, R. U.; AYRES, L. W. (edts.). A Handbook of Industrial Ecology. UK: Edward Elgar Publishing, 2002, p. 3-15.

LÓPEZ, A. Competitividad, innovación y desarrollo sustentable: una discusión conceptual. Buenos Aires: CENIT, 1996.

LUSTOSA, M. C. J. Inovação e tecnologia para uma economia verde: questões fundamentais. Política Ambiental, n. 8, p. 111-122, jun. 2011.

NELSON, R.; WINTER, S. In search of useful theory of innovation. Research Policy, v. 6, n. 1, p. 36-76, 1977.

OECD. Green Growth: Overcoming the Crisis and Beyond. Paris, OECD, 2009a. Disponível em: <http://www.oecd.org/env/43176103.pdf>. Acesso em: jan. 2016.

OECD. Sustainable manufacturing and eco-innovation: towards a green economy. OECD, 2009b. Disponível em: <http://www.oecd.org/env/consumption-innovation/42957785.pdf>. Acesso em: jan. 2016. 
O'ROURKE, D.; CONNELLY, L.; KOSHLAND, C. Industrial Ecology: a critical review. International Journal of Environment and Pollution, v. 6, n. 2-3, p.89-112, 1996.

PACHECO, J. M. Ecossistemas Industriais: proposição de estrutura analítica e avaliação do complexo sucroalcooleiro do Triângulo Mineiro. 2013. 210 f. Dissertação (Mestrado em Economia) - Programa de PósGraduação em Economia, Instituto de Economia, Universidade Federal de Uberlândia, Uberlândia, 2013.

PEARCE, D. W.; MARKANDYA, A.; BARBIER, E. B. Blueprint for a sustainable economy. Earthscan: London, 1989.

PORTER, M. E.; VAN DER LINDE, C. Toward a New Conception of the Environment-Competitiveness Relationship. The Journal of Economic Perspectives, v. 9, n. 4, p. 97-118, 1995.

RENNINGS, K. Towards a theory and policy of Eco-Innovation: neoclassical and (co-) evolutionary perspectives. Center for European Economic Research. ZEW Discussion Paper 98-24, jul. 1998.

RENNINGS, K. Redefining innovation - eco-innovation research and the contribution from ecological economics. Ecological Economics, v. 32, n. 2, p. 319-332, 2000.

SACHS, I. Sociedade, cultura e meio ambiente. Mundo \& Vida, v. 2 n. 1, p. 713, 2000.

TIBBS, H. Industrial Ecology: an environmental agenda for industry. Global Business Network, 1993.

UNEP. Green Economy: developing countries stories. Geneva: UNEP, $2010 . \quad$ Disponível em: $<$ http://www.unep.org/pdf/greeneconomy_successstories.pdf>. Acesso em: jan. 2016.

UNEP. Towards a green economy: pathways to sustainable development and poverty eradication. A synthesis for policy makers. UNEP, 2011. Disponível em: <http://www.ipu.org/splz-e/rio+20/rpt-unep.pdf>. Acesso em: jan. 2016. 